\title{
Long-Term Monitoring of Hippocampus-Dependent Behavior in Naturalistic Settings: Mutant Mice Lacking Neurotrophin Receptor TrkB in the Forebrain Show Spatial Learning But Impaired Behavioral Flexibility
}

\author{
Alexei L. Vyssotski, ${ }^{1,2}$ Giacomo Dell'Omo, ${ }^{1,3}$ \\ Inga I. Poletaeva, ${ }^{4}$ Dmitri L. Vyssotski, ${ }^{1,2}$ \\ Liliana Minichiello, ${ }^{5}$ Rüdiger Klein, ${ }^{5}$ \\ David P. Wolfer, ${ }^{1}$ and Hans-Peter Lipp ${ }^{1 *}$ \\ ${ }^{1}$ Division of Neuroanatomy and Behavior and \\ Neuroscience Center, Institute of Anatomy, University of \\ Zürich, Zürich, Switzerland \\ ${ }^{2}$ P.K. Anokhin Institute of Normal Physiology, Russian \\ Academy of Sciences, Moscow, Russia \\ ${ }^{3}$ Laboratory of Veterinary Medicine, Istituto Superiore di \\ Sanità, Rome, Italy \\ ${ }^{4}$ Laboratory of Physiology and Genetics of Behavior, \\ Faculty of Biology, Moscow State University, \\ Moscow, Russia \\ ${ }^{5}$ European Molecular Biology Laboratory, \\ Heidelberg, Germany
}

\begin{abstract}
Previous behavioral studies (Minichiello et al., Neuron 1999;24:401-414) showed that mice deficient for the TrkB receptor in the forebrain were unable to learn a swimming navigation task with an invisible platform and were severely impaired in finding a visible platform in the same setup. Likewise, additional behavioral deficits suggested a malfunction of the hippocampus and proximally connected forebrain structures. In order to discriminate whether the behavioral impairment was caused either by deficits in spatial memory and learning, or alternatively by loss of behavioral flexibility, 8 trkB mutant, 13 wild-type, and 22 heterozygous mice were implanted with transponders and released for 21 days into a large outdoor pen $(10 \times 10 \mathrm{~m})$. The enclosure contained 2 shelters and 8 computer-controlled feeder boxes, delivering food portions for every mouse only during their first visit. Every third day, mice received food ad libitum inside the shelters. All mice learned to patrol the boxes correctly within a few days. However, significant differences emerged during those days with free food available. Wild-type mice remained inside the shelters, while all homozygous mutants continued to patrol the
\end{abstract}

Grant sponsor: Swiss National Science Foundation; Grant numbers: 31 57139.99, Institutional Partnership Grant 7IP062645; Grant sponsor: European Union; Grant number: Biotechnology Network Grant BIO4CT980297/BBW98.0125; Grant sponsor: NCCR "Neural Plasticity and Repair."

Present address for Liliana Minichiello: European Molecular Biology Laboratory, Monte Rotondo, Rome, Italy.

*Correspondence to: Dr. H.-P. Lipp, Institute of Anatomy, University of Zürich-Irchel, Winterthurerstrasse 190, CH-8057 Zürich, Switzerland.

E-mail: hplipp@anatom.unizh.ch

Accepted for publication 1 August 2001 boxes in their habitual way, the heterozygous mutants showing intermediate scores. These and previous data suggest that one of the natural functions of the mouse hippocampus is to comediate behavioral flexibility, and that TrkB receptors might play an essential role in maintaining the neuronal short-term plasticity necessary for this capacity. Hippocampus 2002;12:27-38. () 2002 Wiley-Liss, Inc.

KEY WORDS: brain-derived neurotrophic factor; TrkB receptor; conditional knockout mouse; hippocampus; spatial learning; water maze; radial maze; radial maze analogue; natural learning; neocortex; ecology

\section{INTRODUCTION}

The tyrosinase kinase receptor B (TrkB) binds to neurotrophins such as the brain-derived neurotrophic factor (BDNF) and neurotrophin-4 (NT-4) and, to a lesser extent, to neurotrophin-3 (NT3) (Henderson, 1996). Most functions of the neurotrophins are mediated by the Trk family of tyrosine kinase receptors (Barbacid, 1995). Developmentally, neurotrophins are important for the survival of sensory and sympathetic neurons before and during target innervation (Henderson, 1996; Conover and Yancopoulos, 1997), while direct survival functions 
as assessed by targeted deletions in mice are less evident in the intact central nervous system (Minichiello et al., 1999). During later postnatal development, neurotrophins regulate the activitydriven reorganization of the lateral geniculate nucleus and of the ocular dominance columns in the neocortex (Bonhoeffer, 1996; Huang et al., 1999; Katz and Shatz, 1996).

In the adult brain, there is evidence for neuroprotective functions of neurotrophins after injuries (Saarelainen et al., 2000), but the role of neurotrophins in seizure-induced sprouting of hippocampal mossy fibers is not clear (Bender et al., 1998; Duman and Vaidya, 1998). A rapidly growing body of evidence indicates that neurotrophins are important for short-term and long-term synaptic transmission, memory, and learning. For example, BDNF causes depolarization of hippocampal neurons at extremely low concentrations (Kafitz et al., 2000), is secreted in an activity-dependent manner (Thoenen, 2000), and has been shown to modulate hippocampal long-term potentiation (LTP), possibly involving both postynaptic and presynaptic mechanisms (Korte et al., 1998; Lu and Gottschalk, 2000; Xu et al., 2000). The role of BDNF in hippocampus-dependent memory and learning has revealed mixed results thus far. Heterozygous BDNF knockout mice have been found to be either impaired (Linnarsson et al., 1997) or normal (Montkowski and Holsboer, 1997). Likewise, studies of BDNF upregulation and/or blocking by means of antisense oligonucleotides in rats subjected to hippocampal tasks reported either evidence for BDNF functions (Kesslak et al., 1998; Mu et al., 1999; Pham et al., 1999; Mizuno et al., 2000), unclear correlations (van Praag et al., 1998), or contradictory result (Cirulli et al., 2000). Most studies in transgenic mice had to be conducted in heterozygous animals, however, because mice with homozygous deletions of BDNF and of the Trk receptor family are not viable, and might thus have undergone differential developmental compensations for behavioral deficits due to reduced levels of BDNF. In rats, the variability of the data appears to be most likely a function of differential methodology.

More recently, however, viable mutant mice with conditional deletion of the $\operatorname{trk} B$ gene have been generated which lack the TrkB receptor in the forebrain only (Minichiello et al., 1999). These mutants suffer from a reduction of TrkB protein by about $85 \%$ in the hippocampus, amygdala, striatum, and neocortex, while it is still expressed in inhibitory interneurons. Postmitotic excision of the $\operatorname{trk} B$ gene starts at about postnatal day 20. Heterozygous mice show an approximate twofold reduction of $\operatorname{TrkB}$ as compared to wild-types, indicating a gene-dosage effect. The mutant mice do not show structural anomalies, except for a slight reduction in myelination and a slightly thinner visual neocortex with normal cytoarchitecture. Hippocampal LTP at CA1 synapses were impaired in mutants, with heterozygotes falling between mutants and wild-types.

The most striking behavioral deficit of the $\operatorname{trkB}$ mutants was their inability to learn the classical Morris water maze task. Equally impressive was their impairment in learning to swim to a visible platform, after having been trained and thus adapted to the setup for 30 trials in the version with the invisible platform. Most mutants needed up to eight trials to learn this new yet easy task, which was mastered by wild-types in most cases during the first trial (Fig.
1). They were also trained in another standard test for hippocampal function, the radial maze. Here the mutants performed significantly worse than wild-types, although they showed significant improvement over time. The heterozygous mice showed learning scores in between, but could not be discriminated statistically from wild-types. During two-way avoidance learning, the trkB mutants soon developed locomotor hyperactivity which entailed (nonsignificant) superior learning as compared to wild-types and heterozygotes, which learned the task without increasing locomotor activity. $\operatorname{trk} B$ mutants also show slight hyperactivity and reduced habituation on an elevated null maze (Huber et al., unpublished data). On the other hand, trkB mutants were comparable to wildtypes in large open fields and in less complex passive-avoidance tasks (Minichiello et al., 1999). They were significantly impaired in acquiring an immobility response in contextual fear conditioning, but showed normal freezing behavior after 24 and 72 h (Vissotsky et al., unpublished data).

Given the distribution of the $\operatorname{TrkB}$ receptors in the forebrain, it was evident that the behavioral impairments of trkB mutants contained many elements of the classical hippocampal lesion syndrome in rodents: failure to learn the Morris water maze, hyperactivity during two-way avoidance learning, and impaired radial maze learning. Other symptoms corresponded to lesion effects in the striatum and entorhinal and frontal cortex, structures proximally connected with the hippocampal formation.

From an observational point of view, however, it appeared that the mutant mice suffered from a general deficit in behavioral flexibility most evident in complex and/or stressful tasks (water maze, radial maze, shuttle-box, and acquisition of conditioned fear responses). Procedural memory (how to do it) and long-term memory for fear-related events appeared to be less affected. Thus, the functionally relevant deficit caused by removal of $\mathrm{TrkB}$ receptors in the forebrain appeared to be a systematic inability to cope with rapidly changing situations. This would imply three points:

1. Besides modulating spatial memory and learning, the hippocampus might covertly participate in a forebrain network governing the ability to select and stabilize ongoing behavioral strategies, and orchestrate smooth transitions between strategies. This capacity shall be denoted here as "behavioral flexibility." Brain structures involved in this process include all higher-order associative cortex regions: for the cognitive-executive level, the prefrontal cortex; for the cognitive-perceptive level, parietal and temporal cortex regions; and the hippocampus in between, straddling executive and perceptive systems. Subcortical components would include the cortico-cortical feedback loops passing through the basal ganglia, hypothalamus, rostral brain stem, and cerebellum that all converge on motor output systems, but also ascending control systems such as the intralaminar system of the thalamus and monoaminergic projections. For details, see Lipp and Wolfer (1998). The common behavioral deficit observable after impaired interaction of systems would thus be the inability to orchestrate behavioral change.

2. Such impairments at the systems level might occur without changes of synaptic plasticity at the cellular level, e.g., after developmental misrouting of forebrain connections. However, a com- 

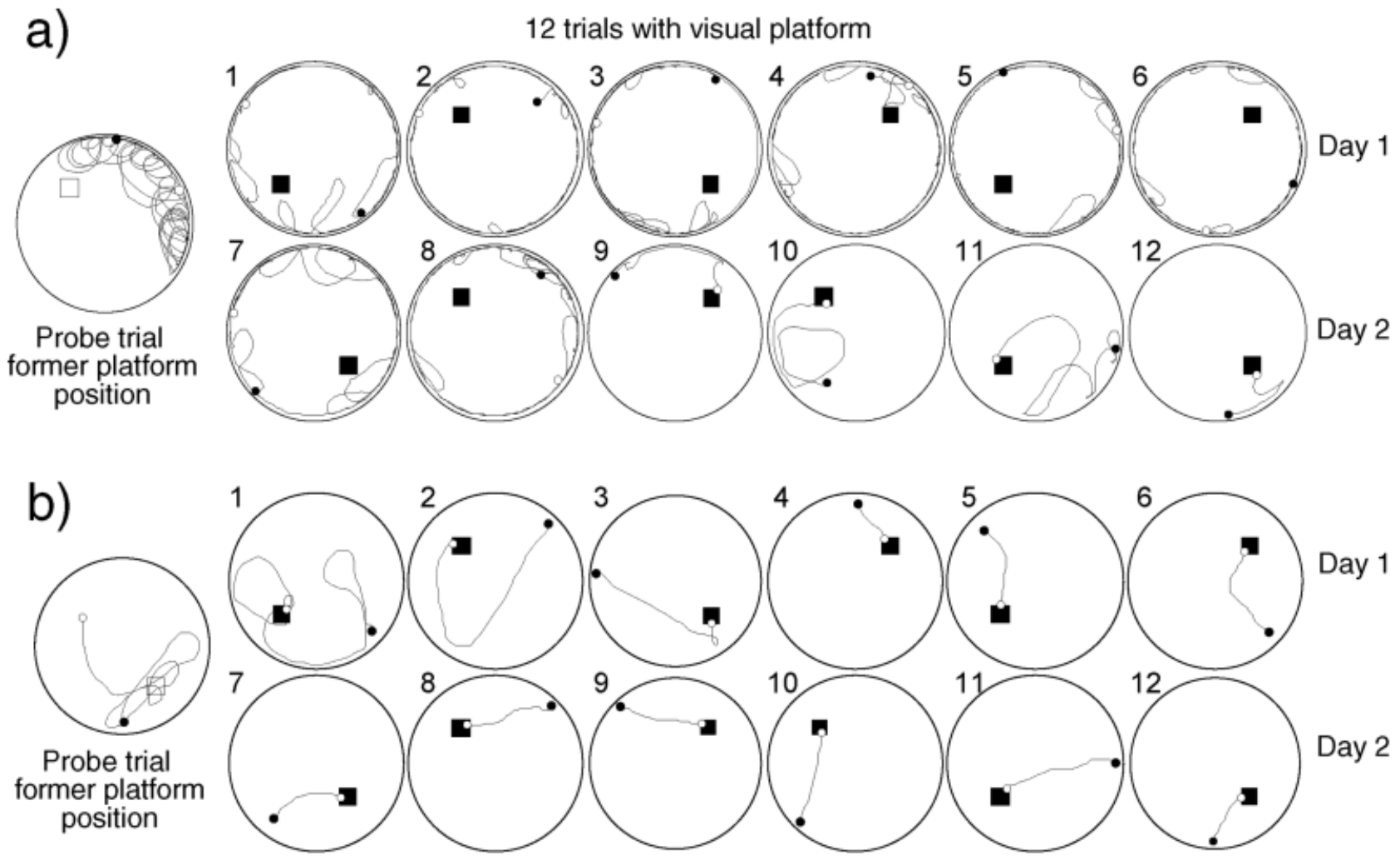

FIGURE 1. Excessive wall swimming (thigmotaxis) of trkB-CRE mice even during cued water escape learning. a: Representative swim paths of a trkB-CRE mouse learning to find a flagged (yet submerged) platform after having been (unsuccessfully) trained for 30 trials to find a fully invisible platform. During that training, it had adopted persistent wall swimming, preventing acquisition of the task. The first single pool diagram at left shows the paths during a probe trial conducted after 18 learning trials, indicating absence of any spatial preference with respect to the invisible platform. Excessive wall swimming

mon impairment of synaptic plasticity in forebrain structures should exacerbate the deficits in behavioral coordination and become visible as a severely impaired behavioral flexibility in a variety of situations, independent of the molecular causes of the deficits. 3. For the TrkB-deficient mutants tested here, this concept would explain their excessive thigmotactic behavior as a malcoordination syndrome caused by forebrain-specific damage to a cellular mechanism important for synaptic plasticity. However, the moderate or missing deficits in nonspatial memory tasks imply that spatial memory per se was not much affected by lack of trkB receptors in the forebrain. A lingering debate is whether thigmotaxis is a mechanism independent of spatial memory, or whether mice swim along the walls because they cannot develop spatial memory. The question cannot be solved in mutants showing strong thigmotaxis preventing learning of the task, because both measures will remain inextricably correlated. The only way to solve the problem is to test mutants for spatial memory and behavioral flexibility outside of the water maze.

Dissociating spatial learning from behavioral flexibility in mutant mice cannot be easily done in the laboratory, chiefly because recognizing and quantifying behavioral routines require prolonged persisted during many trials of visually cued learning. Eventually, the mutant mouse oriented towards the flag, indicating that it was aware of it and capable of procedural learning. $b$ : Same sequence in a wildtype control. Note the clear searching over the platform during the probe trial, and the immediate reaction to the flag in the pool, the usual reaction of mice in this situation. Solid dots indicate release position; open dots, end of swim path. Pool diameter was $150 \mathrm{~cm}$, maximal swim time $120 \mathrm{~s}$. For further details of water maze learning of these mice, see Minichiello et al. (1999).

testing periods. Finally, nonspatial behavioral tasks assessing behavioral flexibility in mice are difficult to design.

We have gathered technical know-how and knowledge of how mice behave, and learn collectively in naturalistic settings (Dell'Omo et al., 2000). Thus, we designed an experiment clarifying the question of whether mice with impaired hippocampusdependent learning behavior would show spatial learning deficits, or suffer predominantly from impaired behavioral flexibility. For testing, homozygous trkB mutants, heterozygotes, and wild-type mice were tagged with identification transponders and released together into a large outdoor pen containing two shelters and eight computer-controlled feeder boxes outside the shelters, providing a radial maze analogue. The daily food portion was then delivered in fractions by the feeders, but only upon the first visit. This forced the mice to learn a daily patrolling habit and abandon multiple visits. Behavioral flexibility was tested repeatedly by including a food place reversal every third day, by offering bowls of unlimited food inside the shelters, the preferred living space of the mice.

In case of impaired short- or long-term spatial learning and memory, or general learning disabilities, one would expect the $\operatorname{trk} B$ mutants to show impaired acquisition of the patrolling task and/or 
less efficient patrolling of the outdoor feeders. In case of a predominant deficit in behavioral flexibility, one would expect few differences in learning to visit the feeders but impaired strategy switching, since previous studies of food place patrolling with normal mice had shown them to prefer food offered in a shelter.

Here we report that $t r k B$ mutant mice indeed show a remarkable deficit in behavioral flexibility, with spatial learning abilities comparable to wild-type controls.

\section{MATERIALS AND METHODS}

\section{Genetic Background and Generation of Transgenic Animals}

The genetic background of the mice was a mixture of about $60 \%$ C57BL/6 (derived from the generation of earlier trkB null mutants backcrossed to C57BL/6, and CamKIIcre transgenic mice), with contributions from the strains $129 / \mathrm{Sv}$ (used to produced mice with lox-P sites flanking trkB for gene excision, and also the trkB null mutants) and from $\mathrm{CBA} / \mathrm{J}$, used for the generation of transgenic $F l p$ mice excising the neo marker in the trkB null mutants. For details, see Minichiello et al. (1999). To inactivate TrkB in the postnatal forebrain, mice heterozygous for a trkB null-mutation but bearing the CamKIIcre transgene were crossed with mice homozygous for lox-P sites flanking the trkB gene. This resulted in wild-types carrying a floxed and a nonfloxed allele, and mutants with a null allele and a floxed allele in combination with $\mathrm{Cre}$ (CreLox), denoted further in the text as "trkB-CRE". Heterozygotes included two types: mice with a wild-type allele and a Cre-lox allele, and mice with a null allele and an allele with lox-P sites only. Hybrid mice transgenic for CRE only were not included in this study, since earlier behavioral testing in the laboratory did not reveal significant differences in comparison to wild-type mice. Nor was there a difference between the two heterozygous subtypes. We also found that trkB mutants generated with two Cre-Lox alleles have the same impairments as the combination of null mutation and Cre-Lox tested here (Ilona Grünberg, unpublished data).

\section{Experimental Animals}

The mice were bred, genotyped, and marked at the European Molecular Biology Laboratory in Heidelberg, from which they were transferred to Russia. Upon arrival at field station "Chisti Lec” (Clear Forest), Pozhnia (Tvier Region, Western Russia), they were left to adapt for 1 week in standard mouse cages placed in a small animal house. In this period, they were lightly anesthetized with methoxiflurane and subcutaneously injected with glass-covered microtransponders (11.5-mm length and 2.2-mm diameter; UKID System, Collinson \& Co., Riverside Industrial Park, Catterall, Preston, UK) by means of a sterile hypodermic needle. Such passive-integrated transponders are routinely used for identification of individual rodents in laboratory and field studies. The mice were then tested for fear conditioning, and left undisturbed for another week. A total of 43 mice (aged between 3-5 months) was released into the experimental pen for 21 days ( 8 mutants, 22 heterzygotes, and 13 wild-types; 24 females and 19 males).

\section{Test Setup}

The experimental pen measured $10 \times 10 \mathrm{~m}$ and was surrounded by a fence made of fine wire mesh (Fig. 2a). Terrestrial predators were kept away by means of an electrically charged wire, as used for cattle fences. During the test period, the pen was covered by a net protecting the mice against avian predators. Two closed shelters of $2 \times 3 \mathrm{~m}$ and $70-\mathrm{cm}$ depth were filled with hay, straw, and branches, providing many small compartments and opportunities for burrowing.

The experimental pen contained eight feeder units (for locations, see Fig. $2 \mathrm{~b}$ ), each one housed in a solid case of grey polyvinylchloride (PVC, $40 \times 40 \times 30 \mathrm{~cm}$ ). The box had an entrance hole on one side which could be barred by means of a sliding gate operated by a motor (Fig. 2c). The entrance gate led to a tubular antenna reading the passive transponder by activating it inductively. Photocells placed at the entrance and exit of the tubular antenna recorded the entries of mice, and operated the entrance gate barring access for other animals. Additional infrared sensors served to verify the presence or absence of a mouse in different parts of the box. After passing the tubular antenna, mice could enter a compartment where food in form of grains (about $0.4 \mathrm{~g}$, one eighth of the daily portion) could be delivered from an automated dispenser. After food consumption, the mice could leave through a mechanical one-way gate barring access from outside. Mice not leaving the feeder were warned first by activating a small computer ventilator of $4-\mathrm{cm}$ diameter producing a weak air stream, and by periodical flashing of a small halogen lamp. After $1 \mathrm{~min}$, a larger ventilator of $11-\mathrm{cm}$ diameter produced a strong continuous air stream. Leaving the box switched off the chasing devices and made it ready for entry by another mouse. Mice reentering the same box activated the warning procedure and chasing actions immediately with their identification.

Each box contained a small $12-\mathrm{V}$ battery to drive the local controller circuitry for electromagnets, photocells, food dispenser, and ventilators. Input/output signals were sent to a multiplexed parallel interface placed in the center of the pen. Similarly, the transponder antennas were scanned continuously by a multiplexer (UKID System, Collinson \& Co.) placed beneath the central interface. Both interfaces were connected to a portable computer located in a shelter near the pen. Input/output signals to and from the central interface were handled through the parallel printer port, i.e., the transponder interface by the serial port. Software modules recorded continuously the number of individual visits, and delivered food upon the first visit but withheld it upon repeated entries. Every $24 \mathrm{~h}$, the data stored on the portable computer were transferred to a nearby laboratory.

\section{Test Schedule and Recorded Variables}

The experiment took place in August, under variable weather conditions. A food delivery cycle started every evening at $8 \mathrm{PM}$. Food was then available during $12 \mathrm{~h}$, no further food being delivered after 8 AM for the next $12 \mathrm{~h}$. A new cycle started every $24 \mathrm{~h}$. 
a)

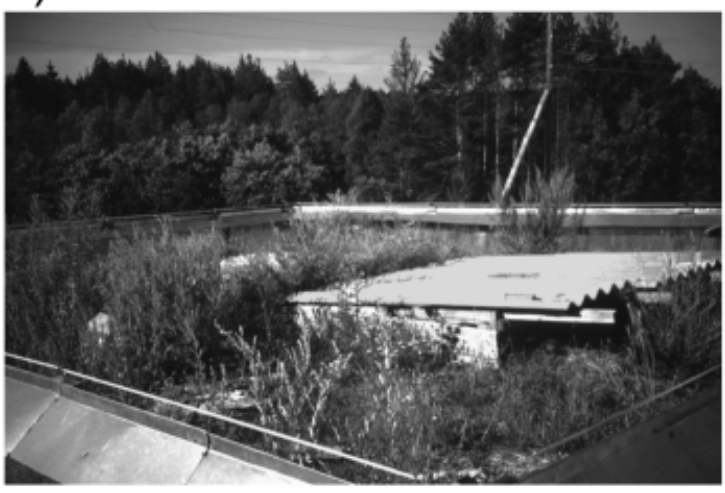

b)

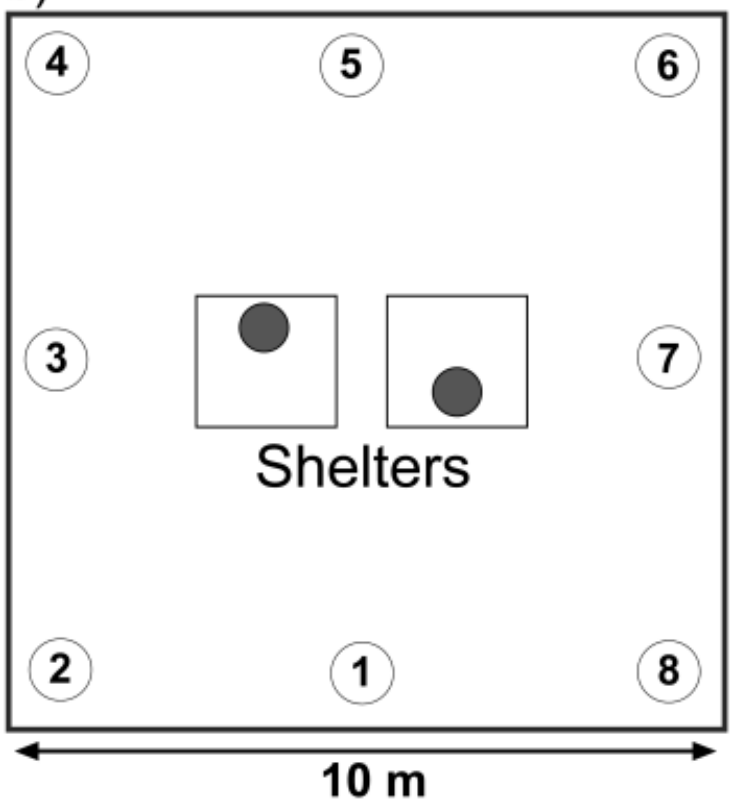

C) Tubular transponder antenna Feeder compartment

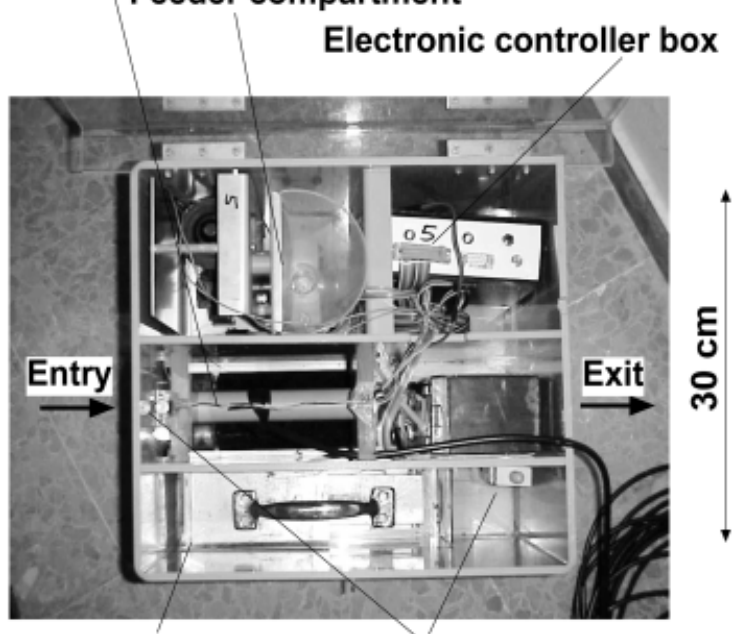

Trap compartment Electromagnetic gates
The standard operation of the feeder boxes started with the release of mice into the pen. During periods of $48 \mathrm{~h}$, food was only available by means of patrolling the feeders. A food place reversal occurred every third day. Bowls with the usual grains were placed inside both shelters with abundant food during $12 \mathrm{~h}$, after which the bowls were removed. This schedule would have also permitted to save mice unable to learning the patrolling task.

The system recorded continuously the number and times of individual visits, whether food was delivered or not, and also the duration of visits and activity patterns during a visit. The data stream was then analyzed offline by a special program. It computed the total number of visits, correct entries (first visits), subsequent entries (errors), and other variables such as the number of correct entries out of the first eight trials (a typical measure of learning in a classical eight-arm radial maze).

\section{Statistics}

Two-way analysis of variance (ANOVA), with genotype as independent factor and daily scores as repeated factor, was applied to the scores from days requiring feeder patrolling, and to the scores from days with free food. Post hoc comparisons were done by means of the Student-Newman-Keuls procedure. The results refer only to mice that were present during the entire test period. Proportionality of animal losses was tested using chi-square procedures, and probabilities of correct entries using Monte Carlo simulation procedures.

\section{RESULTS}

As expected from previous studies, releasing mice born in the laboratory into outdoor pens resulted in disappearance of animals for unknown reasons. Thus, in 17 days, the population declined gradually from 43 to 29 animals and then remained stable. The losses occurred in males and females about equally. Out of 8 trkBCRE mice, 4 disappeared, as well as 7 wild-types out of 13 . The heterozygous animals showed a somewhat better survival (3 out of 22). Chi-square analysis revealed significant differences between genotypes, owing to the lower losses of the heterozygous mice, but showed no difference between trkB-CREmice and wild-types.

Despite the complexity of the new situation, all mice, including the trkB-CRE animals, learned the feeder patrolling in about a week. Afterwards, the learning scores, defined as number of correct entries, increased less steeply, and at the end of the experiment, most mice visited between 7-8 feeders. As evident from Figure 3a, there were no differences between the genotypes $\left(\mathrm{F}_{2,27}=1.18\right.$, n.s.). This equality was not due to an increased number of visits by trkB-CRE mice. They showed, in fact, significantly fewer errors

FIGURE 2. Experimental setup. a: Outdoor pen with two shelters. During experiments, the pen was covered with a net to keep away avian predators. b: Location of feeder boxes delivering food only upon first visit. c: Detailed view of feeder box. 


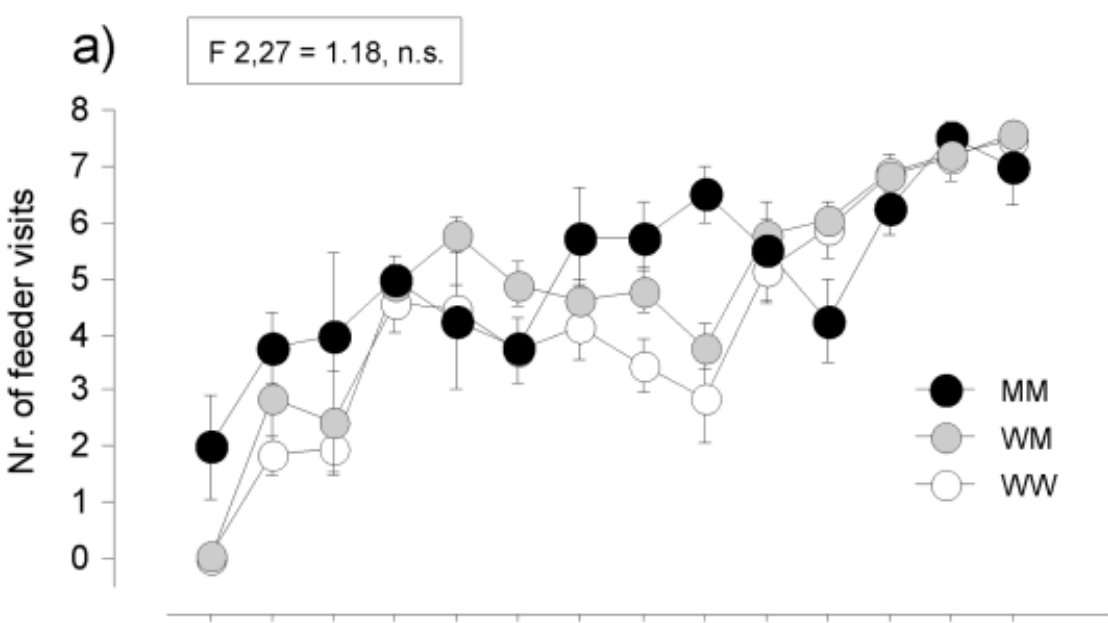

$\begin{array}{llllllllllllll}1 & 2 & 4 & 5 & 7 & 8 & 10 & 11 & 13 & 14 & 16 & 17 & 19 & 20\end{array}$

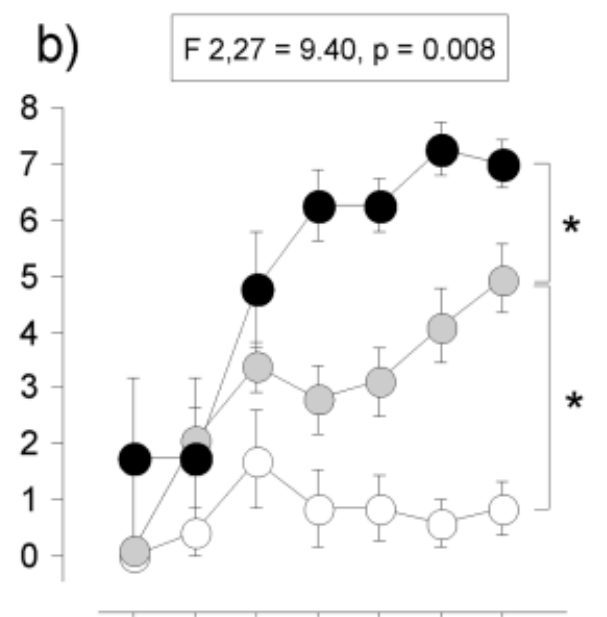

$\begin{array}{lllllll}3 & 6 & 9 & 12 & 15 & 18 & 21\end{array}$

c)

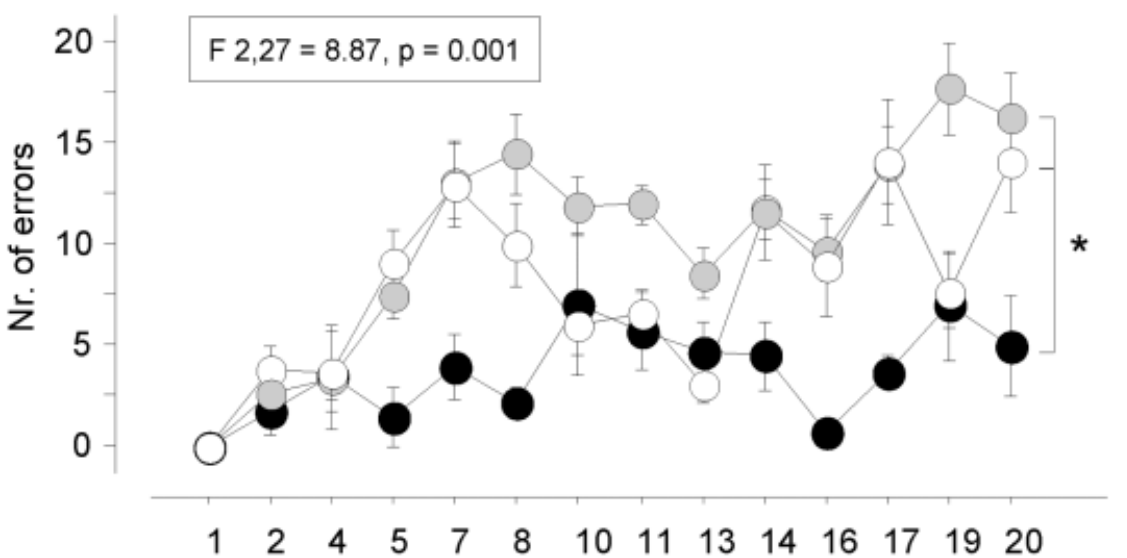

Days with food delivered by outdoor feeders only

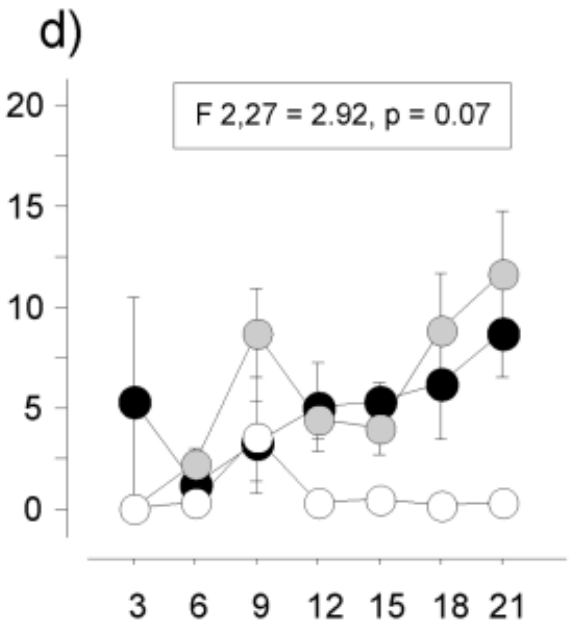

Free food also available inside

FIGURE 3. Long-term behavioral flexibility in trkB-CRE, heterozygous, and wild-type mice. a: Number of feeder visits during days when daily food portion was only delivered upon first entry in an outdoor feeder. trkB-CRE mice acquired patrolling comparable to wild-type mice and heterozygous animals. b: Number of feeder visits during days when additional free food was placed inside both shelters. trkB-CRE failed to change their patrolling habit on those days when it was not required to obtain food. Note also that visit scores of heterozygous mice during days with free food fell significantly in between mutants and wild-types. c: Number of errors (repeated en-

(multiple entries) than wild-types and heterozygotes $\left(\mathrm{F}_{2,27}=8.87\right.$, $P=0.001$ ), which could not be discriminated statistically from each other (Fig. 3c). There were no significant differences related to sex.

The reason for this apparently superior efficiency became clear after analysis of the patrolling behavior during the days with free food (Fig. 3b): during the food place reversals in the first week, all mice visited about two feeders despite the free food inside the shelters. However, after having learned the feeder patrolling, the trkB-CRE mice continued their habitual visits of all feeders, while the wild-type mice barely left the shelter for feeding. As they omit- tries) during days when daily food portion was delivered outdoors only, showing reduced number of errors of $t r k B$-CRE mice. d: Number of errors during days when additional free food was placed inside both shelters. Wild-type mice barely committed errors, as they remained inside. The graph shows only scores (means and SEM) of those animals present till end of testing period (see text), but day-today analysis of visit frequencies, including all mice for a given day, showed nearly identical plots. ${ }^{*} P<0.05$, post hoc comparisons, Student-Newman-Keuls.

ted visits to outdoor feeders, they also committed no errors in form of multiple entries (Fig 3d). On the following days, however, they resumed the patrolling behavior, shifting seamlessly between the two strategies. Interestingly, the heterozygous mice showed an intermediate behavior, visiting regularly some feeders but not to the extent as the homozygous mutants. Statistically, there was a highly significant genotype effect $\left(\mathrm{F}_{2,27}=9.4, P=0.008\right)$, and post hoc comparisons showed that heterozygous mice were significantly different from both wild-types and trkB-CRE mice $(P<0.05$, Student-Newman-Keuls). One should note that analysis of single days, which included all mice present at a given time, showed 
TABLE 1.

Probability of Correct Entries According to Number of Feeder Visits

\begin{tabular}{lccc}
\hline $\begin{array}{l}\text { Feeder positions } \\
\text { in memory }\end{array}$ & $\begin{array}{c}\text { Average correct entries } \\
\text { in first } 8 \text { visits }\end{array}$ & $\begin{array}{c}\text { Probability of } 6.75 \text { correct } \\
\text { entries in first } 8 \text { visits }\end{array}$ & $\begin{array}{c}\text { Probability of } 6.5 \text { correct entries } \\
\text { in first } 8 \text { visits }\end{array}$ \\
\hline 0 & 5.25 & 0.00073 & 0.0048 \\
1 & 5.62 & 0.0068 & 0.033 \\
2 & 5.99 & 0.048 & 0.16 \\
3 & 6.36 & 0.23 & 0.49 \\
4 & 6.73 & 0.64 & 0.87 \\
5 & 7.11 & 0.96 & 1.0 \\
6 & 7.50 & 1.0 & 1.0 \\
7 & 8.00 & 1.0 & 1.0 \\
\hline
\end{tabular}

similar behavioral scores for those mice that disappeared later. Thus, the curves in Figure 3 are representative for the different genotypes.

An analysis of order of visits did not show a tendency of trkBCRE mice for clockwise or counterclockwise patrolling of the feeders; nor was this observed for the other mice (data not shown).

In order to estimate the capacity and duration of short-term positional spatial memory of trkB-CRE mice in a radial maze analogue, the data from days 18 and 21 were analyzed in detail. On those days with free food, trkB-CRE mice made 6.75 and 6.5 correct visits from the first 8 on average (on days 18 and 21, respectively), while wild-type mice were feeding inside. What might be the minimal number of feeder sites whose position must be kept in memory to explain the performance of the trkB-CRE mice? An answer can be derived from Table 1, calculated by means of Monte Carlo methods. It presents the probabilities of correct entries, assuming memorization of $0-7$ places visited earlier. Using the same procedures, it also shows the probabilities of 6.75 and 6.5 correct visits of the four trkB-CRE mice (Table 1).

For the day with an average of 6.75 correct entries (out of the fist 8 visits), the table indicates that trkB-CRE mice memorized the position of at least three previously visited feeders. For the day with an average of 6.5 correct visits, Table 1 infers positional memory of at least two previously visited places. Taking into account variations in patrolling performance, a conservative estimate of two previously visited feeder places appears justified. Note, however, that this calculation applies to heterozygous and wild-type mice as well, showing that the capacity of short-term memory required to solve this task (and other radial maze like tasks) is not excessive.

The duration of short-term positional memory in trkB-CRE mice was estimated by analyzing the time course of feeder visits at day 18 with free food presented inside. On average, trkB-CRE mice took $5 \mathrm{~h}$ and $30 \mathrm{~min}$ to complete eight visits. This would correspond to an approximate interval between visits of about 45 min, indicating that positional memory was conserved over at least $1 \mathrm{~h}$ and $30 \mathrm{~min}$. However, visits occurred in bouts during which they entered 2-3 feeders in intervals of $2-5 \mathrm{~min}$. Nonetheless, analysis of single trkB-CRE mice showing perfect performance of eight correct choices showed the estimate to be correct. For example, the visit pattern of the mouse shown in Figure 4 clearly indi- cates that the animal visited the fifth, sixth, and seventh feeders (whose positions can hardly be found by chance) in shorter intervals ranging from $2-5 \mathrm{~min}$. However, it took a rest of $70 \mathrm{~min}$ (most likely in vicinity of available food nearby) before choosing the last feeder site correctly.

The detailed analysis of visit patterns also showed that the errors committed by the trkB-CRE mice occurred mainly after having visited most boxes successfully. Failure of food reward was usually followed by a quick bout of further feeder visits, taking place in short intervals of $1-3 \mathrm{~min}$.

\section{DISCUSSION}

This experiment shows that trkB-CRE mice are able to learn a spatial task, including appropriate behavior inside the rather com-

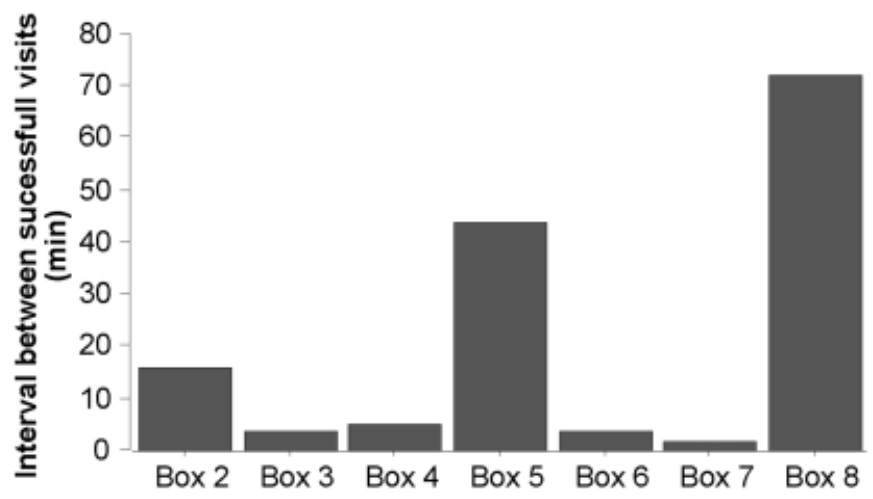

FIGURE 4. Intervals between visits as observed in a trkB-Cre mouse completing eight successive correct choices on a day when free food was available within shelters. Recording of intervals started with the first box visit, not shown in the plot. Boxes 3 and 4 were visited after 4 and 5 min, respectively. A new bout of visits started $44 \mathrm{~min}$ later, boxes 6 and 7 being visited at intervals of 4 and $2 \mathrm{~min}$, respectively. The last remaining box was found after a pause of $70 \mathrm{~min}$. Up to box 5 , correct choices can be attributed to search performance at chance level (see also Table 1), but the correct visits at boxes 6-8 indicate positional short-term (working) memory lasting more than $1 \mathrm{~h}$. 
plex feeder boxes. However, having once learned the procedure, they appear to be unable to shift quickly to another seemingly easier and adaptive strategy. This confirms our previous interpretation of laboratory tests, namely that the lack of TrkB receptors in the forebrain of mice primarily affects their behavioral flexibility, sparing simple spatial learning and task-specific memories. The new finding here is the demonstration of a dissociation between behavioral flexibility and natural spatial learning, and the significantly intermediate scores of heterozygous mutants. We shall discuss first the conclusions pertinent to these data, and afterwards offer some general conclusions and perspectives.

\section{Behavioral Impairments in Naturalistic Settings Correspond to Observations in Laboratory Tests But Deemphasize the Role of Spatial Learning and Memory}

Our data suggest that trkB-CRE mice are able to learn a radial maze analogue, albeit on a much larger scale of space and time than in conventional radial maze tasks. This does not exclude a moderate impairment of spatial memory and learning, because analysis of the short-term memory capacity required to solve the task showed that it is rather modest. One might object that mutant mice might have learned the task by occasionally following other mice. However, this appears unlikely because correct patrolling depends on the individual chosen sequential visits starting at different feeders. Thus, following another mouse would imply that the follower has knowledge that he is trailing a companion heading towards a correct target. Likewise, their low number of reentry errors implies that they are not handicapped in slowly acquiring a rather complex procedural and spatial task. Their visits were stretched over several hours, which at least suggests that they remembered the position of a few previously visited boxes over $2 \mathrm{~h}$. Elsewise, they should have learned to avoid their recent own odor at the entry of a box. Theoretically, trkB-CRE mice might have been prevented by wildtype and heterozygous mice to access the bowls with free food. However, in other experiments monitoring such free food sites, we found that they are not occupied permanently by mice. It is difficult to find another explanation for the amazingly impaired strategy switching of the mutants than to assume that the lack of TrkB receptors caused a massive deficit in their behavioral flexibility, probably at a higher cognitive or executive level, since trkB-CRE mice do not show sensory or motor anomalies.

The results of this experiment fit rather well with previous studies in the laboratory which had shown that trkB-CRE mice were able to learn simple procedural tasks such as arm patrolling in the radial maze or passive avoidance. They showed increased behavioral stereotypy when facing stressful (shuttle-box) and/or complex learning tasks (water maze), and appeared slightly hyperactive on the elevated null-maze, but were normal in basic locomotor activity and passive avoidance paradigms. Task-specific long-term memories appeared to be grossly intact. However, spatial memory and learning under natural conditions appeared to be intact (or the deficits more discrete) than was concluded from observations in the water maze. Why should this be so?

\section{Behavioral Flexibility vs. Spatial Memory in the Water Maze}

The most striking parallel observations in the laboratory and in a real-world setup were the persistent thigmotaxis of trkB-CRE mice in the water maze, and the stubbornness of mutants in executing acquired complex patrolling routines. There is one exception: in the water maze, heterozygotes could not be discriminated from wild-types, while performance in the radial maze was intermediate between homozygous mutants and wild-types but not statistically significant.

One can safely assume that lack of TrkB receptors in excitatory neurons should entail at least partial malfunction of the hippocampus in mutant mice. BDNF occurs in high concentrations in the hippocampus, and trkB-CRE mice showed deficits in LTP at CA1 synapses (Minichiello et al., 1999). We discussed elsewhere in detail that the cognitive deficits characterizing trkB-CRE mice are best explained by assuming malfunction of short-term synaptic plasticity within an interconnected network including the hippocampus, prefrontal and entorhinal cortex, ventral striatum, amygdala, and thalamu (in particular, limbic and intralaminar nuclei). The involvement of several structures is thus likely to aggravate the deficit, which has been termed "hippocampal plus" syndrome (Minichiello et al., 1999). One may also assume similar yet modality-specific deficits in specialized regions of the neocortex and dorsal striatum, which are of little relevance for complex tasks. In terms of memory, one would expect deficits in multimodal associative and perhaps episodic memory (Minichiello et al., 1999).

For trkB-CRE mice, these new data strongly imply that many of the measures in the water maze, thought to reflect hippocampusdependent spatial learning and memory processes, relate to degree of behavioral flexibility permitting strategy switching. We showed elsewhere that thigmotaxis is one of the major factors determining the acquisition of water maze learning in transgenic mice (Wolfer et al., 1997; Lipp and Wolfer, 1998; Wolfer and Lipp, 2000). It is an initial, primitive escape strategy which is either followed by a controlled search strategy eventually leading to finding the platform, or transforms into stereotyped circular swimming paths parallel to the walls (chaining), and occasionally into passive floating. These less efficient strategies are ultimately successful as well, because the mice are rescued after a limited period, and can thus be classified as procedural learning. On the other hand, the position of the platform, once found, appears to be remembered rather well, but mice must learn the procedure to find it rapidly. This can take considerable time, because mice tend to regress to their first primitive strategies unpredictably, according to recognizable or unidentified events. Thus, performance levels in water maze acquisition are largely determined by the ability of mice to maintain appropriate and suppress previously acquired strategies even under stressful situations, i.e., by their degree of behavioral flexibility. Minor variations of measures of spatial memory in the water maze itself are statistically independent of the degree of thigmotaxis (Lipp and Wolfer, 1998), but in cases of strongly reduced flexibility, assessing spatial memory by means of probe trials is often confounded. For example, it is impossible to discriminate whether reduced search- 
ing over a former platform position is caused by defective spatial memory or by increased behavioral flexibility. Likewise, mice not finding an expected platform often regress to previous strategies, which can be misinterpreted as a spatial memory deficit. It is thus conceivable that the inability of trkB-CRE mice to learn the water maze was not caused by defective spatial memory.

The data are less clear with respect to heterozygous mutants, who learned the water maze as efficiently as wild-types, but were intermediate in the outdoor task. Why? The most likely explanation is that water maze learning is kind of an all-or-none phenomenon. Once mice find the platform, rapid improvement in platform finding is shown also by mice with targeted deletions having moderate effects on learning (Gass et al., 1998). This could explain why heterozygous mice in the water maze were not much different from wild-types. Another point is that the intermediate behavior of heterozygous mutants in the outdoor pen took 10 days to emerge. In comparison, assessment of noncued and cued water maze learning was done in small intervals of $120 \mathrm{~s}$ during 7 days, six times a day (Minichiello et al., 1999).

\section{What Are the Synaptic Correlates of Behavioral Flexibility?}

A straightforward interpretation of the synaptic mechanisms underlying the deficits in trkB-CRE mice is not possible at present. For one thing, $\operatorname{TrkB}$ receptors in inhibitory interneurons are spared. Secondly, the multiple functions of BDNF (see Introduction) complicate an analysis. As the formation of simple long-term memory appears not to be affected, both in the laboratory and under natural conditions, some of the mechanisms relevant for behavioral flexibility must be linked to the faster processes associated with NBDF and trkB receptors: synaptic transmission (Kafitz et al., 2000), LTP (Korte et al., 1998, 2001; Lu and Chow, 1999; $\mathrm{Xu}$ et al., 2000), or other mechanisms of short-term stabilization (McAllister et al., 1999). It was argued in the Introduction that any change of synaptic plasticity in the forebrain circuitry of mutant mice will ultimately be reflected in impaired interactions between systems, appearing phenotypically as impaired behavioral flexibility. Hence one can conclude here only that lack of trkB receptors in excitatory forebrain neurons, including those of the hippocampus, does not interfere substantially with the cellular mechanisms supporting procedural and spatial long-term memory. On the other hand, candidate mechanisms at the cellular level supporting smooth switching between behavioral strategies must operate within a critical time window lasting from minutes to hours. This suggests that a particular molecular function of neurotrophin might be linked to the cellular machinery governing short-term memory and related processes, including habituation. Control of all these processes is essential for orchestrated activation and inhibition of neural systems underlying the phenomenon of behavioral flexibility. From an evolutionary point of view, one would expect in the vertebrate brain the appearance of cellular mechanisms enabling a more sophisticated control of short-term synaptic plasticity than habituation. Interestingly, neurotrophins are not found among invertebrates (McKay et al., 1999).

\section{GENERAL CONCLUSIONS AND PERSPECTIVES}

\section{Is Behavioral Flexibility Mediated by the Hippocampus?}

The notion that the hippocampus also mediates behavioral flexibility and patterning is an old one (Glickman et al., 1970; Isaacson and Kimble, 1972). In fact, many lesion studies in rodents revealed impaired flexibility, e.g., Isaacson (1984), Buzsaki et al. (1989), Leaton and Borszcz (1990), and Lipska et al. (1994), which were mostly interpreted in terms of hippocampal interaction with the prefrontal cortex and basal ganglia. Implicit control of behavioral flexibility was concluded from a quantitative analysis of hippocampal lesion effects on radial maze behavior of rats (Terry and Oakley, 1990). The involvement of the hippocampus in mediating behavioral flexibility is rarely discussed, however. Partly, this is due to difficulties in quantifying behavioral strategies above the level of obvious motor stereotypies. Another reason for this neglect is the somewhat simplistic emphasis on deficits in spatial learning, thought to be a hippocampus-specific indicator for cognitive alterations and memory deficits. At best, observed deficits in behavioral flexibility after lesions or genetic alterations of hippocampal structures are interpreted as "noncognitive" side effects due to interaction with other brain structures.

\section{How Does This Relate to Spatial Learning and Cognition?}

Given the presence of hippocampal place cells, the involvement of that structure in spatial mapping is not disputable. However, our data and other studies indicate a cooperative participation of the hippocampus in a cortico-subcortical network coordinating multiple processing in the forebrain (Lipp and Wolfer, 1998). Malfunction of this system is then primarily reflected in deficits according to the species-specific organization of the brain: impaired acquisition and retrieval of episodic and complex associative memory in larger brains, with increasingly reduced behavioral flexibility in smaller brains. There is no neuroanatomical reason to rule out coexistence of processing and memorizing spatial cues, and orchestration of behavior in the hippocampus. However, one might ask which of the hippocampal subsystems is behaviorally more relevant for the analysis of cognitive deficits in genetically modified mice.

At least for trkB-CRE mice, we have now shown that thigmotaxis is a correlate of reduced behavioral flexibility but is poorly related to spatial learning abilities. It would seem likely that this is also the case for many other genetically modified mice. For example, impaired acquisition of the standard Morris maze was found in mice with reduced levels of truncated $\beta$-amyloid pecursor protein (Müller et al., 1994), in mice deficient for the cyclic AMP response binding protein CREB (Gass et al., 1998), in apolipoprotein knockout mice (Oitzl et al., 1997), and in mice deficient for tissue plasminogen activator (tPA) (Huang et al., 1996). With the possible exception of tPA knockout mice, spatial memory scores were not specifically affected. Likewise, much of the genetic variation in 
water maze learning among mouse strains can be attributed to variations in thigmotaxis (Wolfer and Lipp, 2000). The targeted mutations mentioned above are not hippocampus-specific. However, the hippocampal formation is by far the largest associative cortex of mice, because most of the neocortex is linked to processing of specific modalities. Thus, nonspecific impairment of forebrain structures necessarily causes symptoms of hippocampal malfunction in tests for hippocampus-dependent behavior. However, there is also direct evidence for hippocampal involvement regulating thigmotaxis. Scores for thigmotaxis are rarely measured, but published swim paths of hippocampally lesioned mice and rats often show circular swimming paths in nonlearners, which obviously prevented the acquisition of spatial memory. In those reports, they are interpreted as an inability of spatial learning, but see above. Likewise, variations in hippocampal mossy fiber patterns known to be associated with hippocampal functions correlate moderately with thigmotaxis (Pleskacheva et al., 2000) and place reversal learning in the Morris maze (Schöpke et al., 1991; Bernasconi-Guastalla et al., 1994); further, mice with hippocampal lesions show excessive wall swimming (Mojaheri et al., unpublished observations). Finally, lesions of the mouse hippocampus do not only impair the acquisition of finding an invisible platform, but retard, unlike in rats, learning of cued escape learning (Logue et al., 1997).

Taken together, it appears that in mice, hippocampal malfunction, be it caused by genetic manipulations or invasive changes, seems often to be reflected by deficits in so-called "noncognitive" functions of the hippocampus, while basic spatial abilities may be partially spared. In fact, mice with targeted mutations that impair water maze learning and LTP still show place cells (Rotenberg et al., 1996, 2000; Cho et al., 1998), even when the impairment is specific for CA1 (McHugh et al., 1996). However, place cells appear less frequently and operate less precisely. Given the many occasions on which dissociation between hippocampal LTP and spatial learning has been observed (including the mice here), one might ask whether changes in LTP might correlate better with the hippocampal mechanisms supporting behavioral flexibility.

\section{What Can Be Learned From Studying the Learning Abilities of Genetically Modified Mice in Naturalistic Environments?}

Studying the behavior of genetically modified mice in naturalistic environments is a novel approach. It was undertaken because the behavioral analysis of phenotypic changes in genetically modified mice faces a variety of methodological problems. An example is given by the confounding of behavioral flexibility with spatial learning as discussed above, but there are other problems. The main difficulty is that very little is known about the species-typical requirements for memory and learning in mice, nor about the ways in which malfunctions of brain structures manifest themselves in an environment for which the brain has been tuned (Nadel, 1995; Lee et al., 1998). This, however, is the conditio sine qua non for extrapolating the effects of central nervous system gene deletions to the human brain.
Such an ethological approach is perhaps less attractive for those experimental psychologists who wish to have control over the experimental situation. Whether strict control of experimental situations in behavioral testing is theoretically possible at all is a matter of debate (Gerlai and Clayton, 1999). However, it is certain that most of the available tests to assess memory and learning are designed with the idea of how a mouse ought to behave, and are not concerned much about the way mice actually live and learn in their habitual environment. For example, mice live in relatively closed social groups called demes, are active nocturnally, move along odor trails, and have short generation cycles and a social structure characterized by dominant males. It is thus unsurprising that disproportionately many gene deletions have an impact on the attack latencies of male mice. Likewise, behavioral flexibility, reflecting fine-tuned coordination between cerebral systems supporting the essential behavioral traits of mice, must be of prime importance for them. On the other hand, their way of life requires less spatial cognition than in species roaming complex and large territories. One is thus tempted to ask whether hippocampal functions related to spatial cognition, particularly with respect to visual cues, are truly essential for survival in the ecological niches occupied by Mus musculus. In a more general way, could it be that the hippocampus is multifunctional, tuning species-typical functions according to ecological demands?

The practical advantage of this approach is the automatic longterm monitoring of learning behavior of large numbers of mice, something difficult to achieve in the laboratory, at least at present. Remarkably, one single experiment with minimal surveillance efforts permitted the researchers to verify a functional dissociation between spatial learning and behavioral flexibility. We realize that social interactions may potentially confound interpretation, although we cannot see how they might have affected behavioral flexibility in this study. On the other hand, it is likely that individual problem-solving in test boxes induces confounding factors that equally escape observation by a human observer (Gerlai and Clayton, 1999).

Lastly, this approach should provide us with new ideas and methodologies of how to test mice appropriately in the laboratory, as few laboratories will bother to establish a field station for mouse testing. Thus, we developed test devices monitoring learning in social groups in their home cages, and modified existing learning tests according to their importance in the real world of mice.

\section{Acknowledgments}

We greatly appreciate the technical help of Laszlo Szaras in building the feeder boxes, and the supervision of mouse pens by Valentin and Svetlana Pazhetnov.

\section{REFERENCES}

Barbacid M. 1995. Structural and functional properties of the TRK family of neurotrophin receptors. Ann NY Acad Sci 766:442-458. 
Bender R, Heimrich B, Meyer M, Frotscher M. 1998. Hippocampal mossy fiber sprouting is not impaired in brain-derived neurotrophic factor-deficient mice. Exp Brain Res 120:399-402.

Bernasconi-Guastalla S, Wolfer DP, Lipp H-P. 1994. Hippocampal mossy fibers and swimming navigation in mice: correlations with size and left-right asymmetries. Hippocampus 4:53-64.

Bonhoeffer T. 1996. Neurotrophins and activity-dependent development of the neocortex. Curr Opin Neurobiol 6:119-126.

Buzsaki G, Ryan JP, Isaacson RL. 1989. The effects of unilateral destruction of fimbria-fornix and supracallosal pathways in the rat. Behav Neural Biol 51:278-288.

Cho YH, Giese KP, Tanila H, Silva AJ, Eichenbaum H. 1998. Abnormal hippocampal spatial representations in $\alpha \mathrm{CamKII}^{\mathrm{T} 286 \mathrm{a}}$ and $\mathrm{CREB}^{\alpha \Delta}$ mice. Science 279:867-869.

Cirulli F, Berry A, Alleva E. 2000. Intracerebroventricular administration of brain-derived neurotrophic factor in adult rats affects analgesia and spontaneous behaviour but not memory retention in a Morris water maze task. Neurosci Lett 287:207-210.

Conover JC, Yancopoulos GD. 1997. Neurotrophin regulation of the developing nervous system: analyses of knockout mice. Rev Neurosci 8:13-27.

Dell'Omo G, Ricceri L, Wolfer DP, Poletaeva II, Lipp H-P. 2000. Temporal and spatial adaptation to food restriction in mice under naturalistic conditions. Behav Brain Res 115:1-8.

Duman RS, Vaidya VA. 1998. Molecular and cellular actions of chronic electroconvulsive seizures. J ECT 14:181-193.

Gass P, Wolfer DP, Balschun D, Rudolph D, Frey U, Lipp H-P, Schütz G. 1998. Deficits in memory tasks of mice with CREB mutations depend on gene dosage. Learn Mem 5:274-288.

Gerlai R, Clayton NS. 1999. Analysing hippocampal function in transgenic mice: an ethological perspective. TINS 22:47-51.

Glickman SE, Higgins TJ, Isaacson RL. 1970. Some effects of hippocampal lesions on the behavior of the Mongolian gerbil. Physiol Behav 5:931-938.

Henderson CE. 1996. Role of neurotrophic factors in neuronal development. Curr Opin Neurobiol 6:64-70.

Huang Y-Y, Bach ME, Lipp H-P, Zhuo M, Wolfer DP, Hawkins RD, Schoonjans L, Kandel ER, Godfraind J-M, Mulligan RC, Collen D, Carmeliet P. 1996. Mice lacking the gene encoding tissue-type plasminogen activator show a selective interference with late phase LTP in both Schaffer collateral and mossy fiber pathways. Proc Natl Acad Sci USA 93:8699-8704.

Huang ZJ, Kirkwood A, Pizzorusso T, Porciatti V, Morales B, Bear MF, Maffei L, Tonegawa S. 1999. BDNF regulates the maturation of inhibition and the critical period of plasticity in mouse visual cortex. Cell 98:739-755.

Isaacson RL. 1984. Hippocampal damage: effects on dopaminergic systems of the basal ganglia. Int Rev Neurobiol 25:339-359.

Isaacson RL, Kimble DP. 1972. Lesions of the limbic system: their effects upon hypotheses and frustration. Behav Biol 7:767-793.

Kafitz KW, Rose CR, Konnerth A. 2000. Neurotrophin-evoked rapid excitation of central neurons. Prog Brain Res 128:243-249.

Katz LC, Shatz CJ. 1996. Synaptic activity and the construction of cortical circuits. Science 274:1133-1138.

Kesslak JP, So V, Choi J, Cotman CW, Gomez-Pinilla F. 1998. Learning upregulates brain-derived neurotrophic factor messenger ribonucleic acid: a mechanism to facilitate encoding and circuit maintenance? Behav Neurosci 112:1012-1019.

Korte M, Kang H, Bonhoeffer T, Schuman E. 1998. A role for BDNF in the late-phase of hippocampal long-term potentiation. Neuropharmacology 37:553-559.

Korte M, Minichiello L, Klein R, Bonhoeffer T. 2001. Shc-binding site in the TrkB receptor is not required for hippocampal long-term potentiation. Neuropharmacology 39:717-724.

Leaton RN, Borszcz GS. 1990. Hippocampal lesions and temporally chained conditioned stimuli in a conditioned suppression paradigm. Psychobiology 18:81-88.
Lee DW, Miyasato LE, Clayton NS. 1998. Neurobiological bases of spatial learning in the natural environment: neurogenesis and growth in the avian and mammalian hippocampus. Neuroreport 9:15-27.

Linnarsson S, Bjorklund A, Ernfors P. 1997. Learning deficit in BDNF mutant mice. Eur J Neurosci 9:2581-257.

Lipp H-P, Wolfer DP. 1998. Genetically modified mice and cognition. Curr Opin Neurobiol 8:272-280.

Lipska BK, Jaskiw GE, Weinberger DR. 1994. The effects of combined prefrontal cortical and hippocampal damage on dopamine-related behaviors in rats. Pharmacol Biochem Behav 48:1053-1057.

Logue SF, Paylor R, Wehner JM. 1997. Hippocampal lesions cause learning deficits in inbred mice in the Morris water maze and conditionedfear task. Behav Neurosci 111:104-113.

Lu B, Chow A. 1999. Neurotrophins and hippocampal synaptic transmission and plasticity. J Neurosci Res 58:76-87.

Lu B, Gottschalk W. 2000. Modulation of hippocampal synaptic transmission and plasticity by neurotrophins. Prog Brain Res 128:231-241.

McAllister AK, Katz LC, Lo DC. 1999. Neurotrophins and synaptic plasticity. Annu Rev Neurosci 22:295-318.

McHugh TJ, Blum KI, Tsien JZ, Tonegawa S, Wilson MA. 1996. Impaired hippocampal representation of space in CA1-specific NMDAR1 knockout mice. Cell 87:1339-1349.

McKay SE, Purcell AL, Carew TJ. 1999. Regulation of synaptic function by neurotrophic factors in vertebrates and invertebrates: implications for development and learning. Learn Mem 6:193-215.

Minichiello L, Korte M, Wolfer DP, Kühn R, Unsicker K, Cestari V, Rossi-Arnaud C, Lipp H-P, Bonhoeffer T, Klein R. 1999. Essential role for TrkB receptors in hippocampus-mediated learning. Neuron 24:401-414.

Mizuno M, Yamada K, Olariu A, Nawa H, Nabeshima T. 2000. Involvement of brain-derived neurotrophic factor in spatial memory formation and maintenance in a radial arm maze test in rats. J Neurosci 20:7116-7121.

Montkowski A, Holsboer F. 1997. Intact spatial learning and memory in transgenic mice with reduced BDNF. Neuroreport 8:779-782.

Mu JS, Li WP, Yao ZB, Zhou XF. 1999. Deprivation of endogenous brain-derived neurotrophic factor results in impairment of spatial learning and memory in adult rats. Brain Res 835:259-265.

Müller U, Cristina N, Li Z-W, Wolfer DP, Lipp H-P, Rülicke T, Brandner S, Aguzzi A, Weissmann C. 1994. Behavioral and anatomical deficits in mice homozygous for a modified $\beta$-amyloid precursor protein (BAPP) gene. Cell 79:755-765.

Nadel L. 1995. The psychobiology of spatial behavior: the hippocampal formation and spatial mapping. In: Alleva E, Fasolo A, Lipp H-P, Nadel L, Ricceri L, editors. Behavioural brain research in naturalistic and semi-naturalistic settings: possibilities and perspectives. Dordrecht, Netherlands: Kluwer. p 245-258.

Oitzl MS, Mulder M, Lucassen PJ, Havekes LM, Grootendorst J, Dekloet ER. 1997. Severe learning deficits in apolipoprotein e knockout mice in a water maze task. Brain Res 752:189-196.

Pham TM, Ickes B, Albeck D, Soderstrom S, Granholm AC, Mohammed AH, Russo-Neustadt A, Ha T, Ramirez R, Kesslak JP. 1999. Changes in brain nerve growth factor levels and nerve growth factor receptors in rats exposed to environmental enrichment for one year. Neuroscience 94:279-286

Pleskacheva MG, Wolfer DP, Kupriyanova IF, Nikolenko DL, Scheffrahn H, Dell'Omo G, Lipp H-P. 2000. Hippocampal mossy fibers and swimming navigation learning in two vole species occupying different habitats. Hippocampus 10:17-30.

Rotenberg A, Mayford M, Hawkins RD, Kandel ER, Muller RU. 1996. Mice expressing activated CaMKII lack low frequency LTP and do not form stable place cells in the CA1 region of the hippocampus. Cell 87:1351-1361.

Rotenberg A, Abel T, Hawkins RD, Kandel ER, Muller RU. 2000. Parallel instabilities of long-term potentiation, place cells, and learning caused by decreased protein kinase A activity. J Neurosci Onl 20: 8096-8102. 
Saarelainen T, Lukkarinen JA, Koponen S, Grohn OH, Jolkkonen J, Koponen E, Haapasalo A, Alhonen L, Wong G, Koistinaho J, Kauppinen RA, Castren E. 2000. Transgenic mice overexpressing truncated trkB neurotrophin receptors in neurons show increased susceptibility to cortical injury after focal cerebral ischemia. Mol Cell Neurosci 16:87-96.

Schöpke R, Wolfer DP, Lipp H-P, Leisinger-Trigona M-C. 1991. Swimming navigation and structural variations of the infrapyramidal mossy fibers in the hippocampus of the mouse. Hippocampus 1:315-328.

Terry P, Oakley DA. 1990. The effects of cortical or hippocampal damage on behavioral flexibility in the rat. Psychobiology 18:404-415.

Thoenen H. 2000. Neurotrophins and activity-dependent plasticity. Prog Brain Res 128:183-191.

van Praag H, Qu PM, Elliott RC, Wu H, Dreyfus CF, Black IB. 1998. Unilateral hippocampal lesions in newborn and adult rats: effects on spatial memory and BDNF gene expression. Behav Brain Res 92:2130.

Wolfer DP, Lipp H-P. 2000. Dissecting the behavior of transgenic mice: is it the mutation, the genetic background or the environment? Exp Physiol 85:627-634.

Wolfer DP, Stagliar-Bozizevic M, Müller U, Lipp H-P. 1997. Assessing the effects of the 129Sv genetic background on swimming navigation learning in transgenic mutants: a study using mice with a modified $\beta$-amyloid precursor gene. Brain Res 771:1-13.

Xu B, Gottschalk W, Chow A, Wilson RI, Schnell E, Zang K, Wang D, Nicoll RA, Lu B, Reichardt LF. 2000. The role of brain-derived neurotrophic factor receptors in the mature hippocampus: modulation of long-term potentiation through a presynaptic mechanism involving TrkB. J Neurosci 20:6888-6897. 